Original scientific paper

\title{
IMPACT OF PROPORTIONAL VALVES' DIFFERENCES TO ENSURE UNIFORM MOTION OF HYDRAULIC MOTORS
}

\author{
Tic, V.; Rotovnik, A. \& Lovrec, D. \\ University of Maribor, Faculty of Mechanical Engineering, Smetanova 17, 2000 Maribor, Slovenia \\ E-Mail: vito.tic@um.si, andraz.rotovnik@student.um.si,darko.lovrec@um.si
}

\begin{abstract}
Ensuring uniform motion of hydraulic actuators is one of the most demanding tasks in the field of Hydraulic Drive Technology. Various, more or less demanding and precise, mechanical-hydraulic or electro-hydraulic solutions are used depending on the accuracy requirements of uniform motion. In addition to more precise uniform motion, the electro-hydraulic solutions also enable compensation and elimination of many inequalities.

The paper deals with the issue of ensuring quality uniform motion of hydraulic rotary actuators. To ensure high rotation accuracy, proportional valves are used as cost-effective, continuously operating electrohydraulic valves. At the forefront of the discussion is the influence of different valve characteristics on the uniform rotation, with differences arising from faults in valve manufacturing, valve assembly, or due to different valve degradation. Based on a detailed mathematical model of the system and simulations based on real measured different characteristics of the valves used, the effects of these differences are shown and control methods to eliminate them.

(Received in September 2020, accepted in January 2021. This paper was with the authors 1 month for 1 revision.)
\end{abstract}

Key Words: Uniform Motion, Hydraulic Motor, Proportional Valve, Simulation

\section{INTRODUCTION}

Hydraulic drive control technology is often used on various machines and devices, where forces and motions are provided by a fluid under pressure. This is especially useful in areas where heavy loads are present, and/or they need to be moved quickly. The use of hydraulics for demanding and difficult operating conditions is the simplest and most efficient, as the hydraulic technique ensures a high energy density of hydraulic components and drives. With reliable energy control, hydraulics can also be used for precise applications, e.g. for uniform motion of actuators. Ensuring uniform motion of hydraulic actuators is a relatively demanding control task due to differences in the system. These may occur due to the different characteristics of the components as a result of manufacturing, or due to differences because of degradation of components or uneven external impacts on the system, e.g. an uneven actuator load. Thus, assuring uniform motion of several actuators is, due to different influences, still a challenge in different areas of machines and devices [1-4].

\subsection{Uniform motion of hydraulic actuators}

Uniform motion of hydraulic actuators can be achieved in several ways, depending on the application and requirements. The demand for uniform motion is most significant in cases when external impacts on the system are very uneven, e.g. unequal load on individual actuators, or unbalanced system control. In the case of equal external forces on an individual actuator, the accuracy of uniform motion could also be affected by the production quality of otherwise identical type hydraulic actuators, over which the user would have no influence. Therefore, in almost all cases a synchronization method is used to compensate for the inequalities in the system. In general, solutions for uniform motion of hydraulic actuators can be divided into mechanical-hydraulic and electro-hydraulic solutions, which can produce the highest quality and accuracy of synchronization. One of the prerequisites to achieve uniform motion by the 
electro-hydraulic solution is the use of continuously acting valves, e. $g$ proportional valves, as a cost-effective solution, where the design, construction and characteristics of the valve are most important.

\subsection{Electrohydraulic valves for performing uniform motion}

Electrohydraulic continuously operating valves are divided into three groups: proportional valves, proportional control valves and servo valves. What they all have in common is that the hydraulic output varies with the electrical input signal. Servo valves have the best dynamic properties and linear characteristics, but, on the other hand, they are also the most complex and expensive. Also, proportional control valves, which use closed-loop position control of a valve's spool, are rather complicated and not a low-cost solution. Thus, this paper investigates if the most common proportional directional valves can be used to achieve an adequate quality of uniform motion of hydraulic actuators - in our case, hydraulic motors.

\section{PROPORTIONAL DIRECTIONAL HYDRAULIC VALVES}

Proportional directional valves are continuously operating valves that enable controlling of the direction and speed of hydraulic actuators. The movement of the control spool is more or less proportional to the input signal. The simplest version of a proportional directional valve is shown in Fig. 1. The spool of the valve is controlled directly by the proportional coil. The position of the spool is defined by the ratio of the spring force and force of the coil and the friction force on the spool. When the coil is energised, the spool moves in the opposite direction until the equilibrium state of the coil force and the spring force is reached.

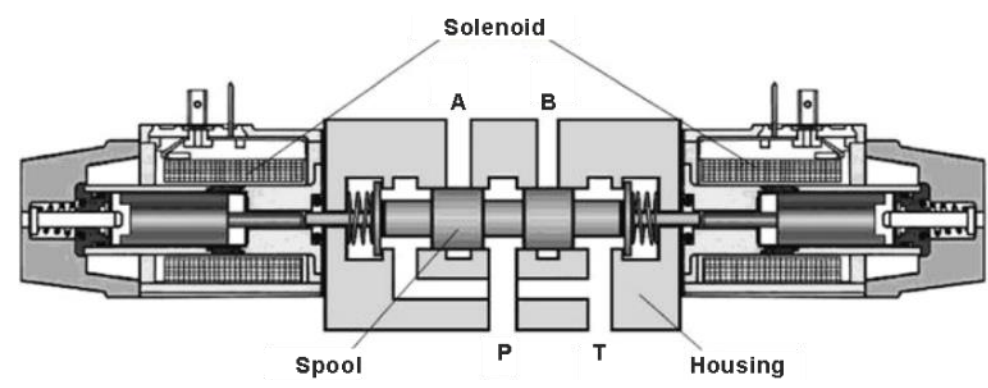

Figure 1: Directly actuated proportional directional control valve without position control [5].

In order be able to hold load at the centre position, they are usually made with a small positive overlap, therefore, the slider overlap is greater than the width of the connected chamber that closes it. In comparison to a zero overlap valve, the dynamics of such a valve are lower, because to change the output value, the slider must be moved by a certain "dead" zone, which is equal to the length of the overlap. Such design is used in most conventional and common proportional valves.

\subsection{Valve characteristics}

In order to achieve uniform motion of hydraulic actuators by using proportional directional valves, it is essential to know the valve's characteristics and all features that affect the operation of the valve directly and, thus, the control of the actuator: spool lap condition, dead zone, flow gain, linearity, hysteresis, transfer function and frequency response.

\subsection{Measurement of valve characteristics}

Additionally, it is also important to know the actual characteristics of the valve to select valves with as similar characteristics as possible. In this way, special attention will be paid to valve 
selection, as we want to have valves with the most identical behaviour, and thus ensure the best possible synchronization of motion. In this case, the controller will only take care of eliminating minor deviations during the motion of the actuators.

Three identical proportional directional valves (Hawe NSWP 2G 20) are used in the given research. They have a positive overlap and are equipped with proportional magnets. Given the positive overlap, a certain dead zone and poorer valve response to smaller signals is to be expected. However, given the fact that these conventional directional valves are equipped with proportional magnets, we can also expect a wider hysteresis, as well as asymmetry in their behaviour when controlling the spool from one side to another.

The characteristics of the valves were measured according to the ISO 10770 standard, for which an automatic measuring system was built [6]. In this way, we obtained the actual characteristics of three completely identical types of valves (valves 1,2 and 3). One of the most important characteristics measured - output flow versus input signal at constant valve pressure drop, is shown in Fig. 2.

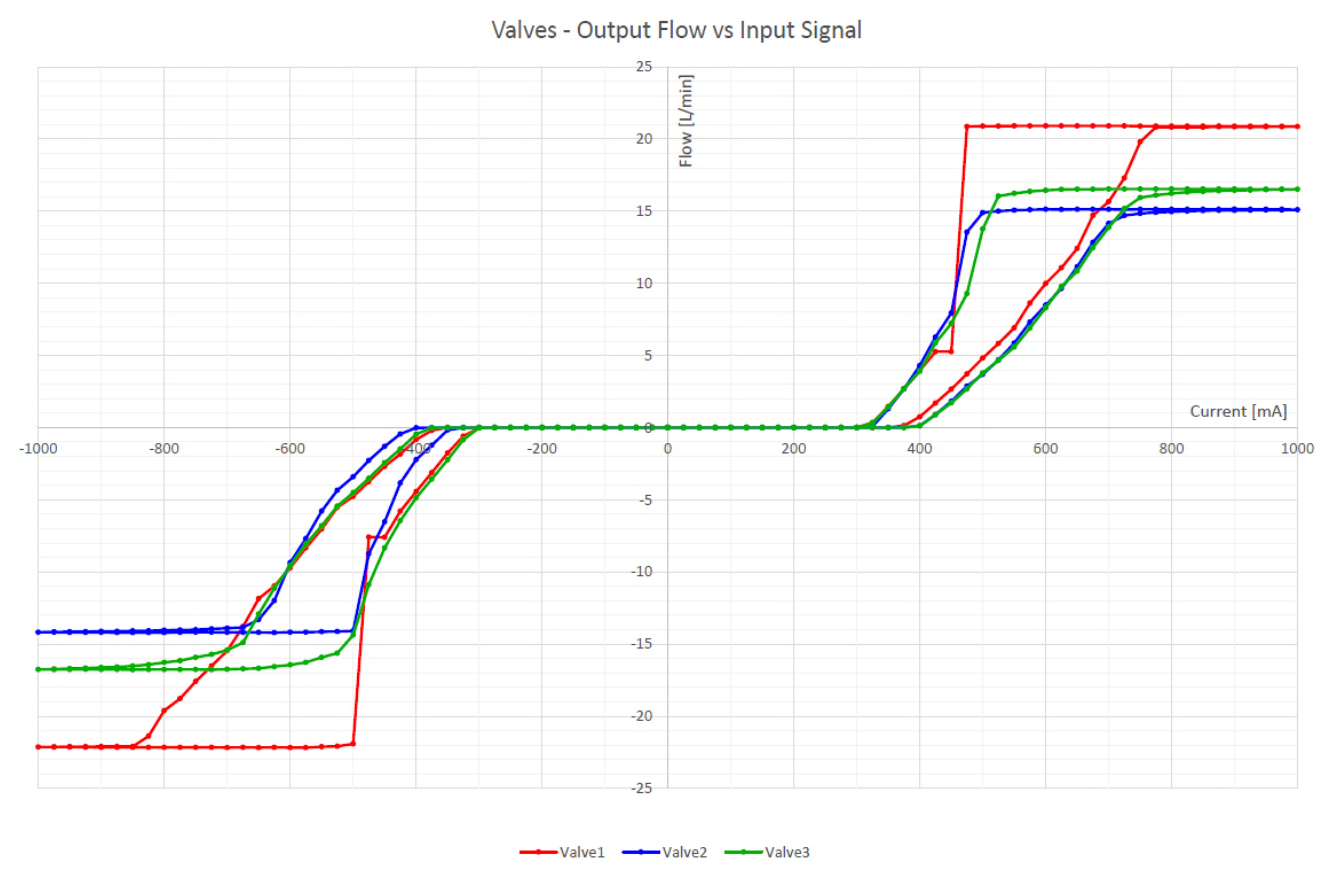

Figure 2: Actual output flow versus input signal (measurement) for three identical type proportional directional valves [6].

Fig. 2 can help us to understand the properties of the valves and their effects on the valves' operation. By the positive overlap of the spool of the valve there is no hydraulic flow up to $300 \mathrm{~mA}$ on the coil of the valve. The output flow starts appearing at around $400 \mathrm{~mA}$, and is fairly linear, increasing up to $730 \mathrm{~mA}$. As the control current decreases and the P-A connection closes, the falling curve is not aligned completely with the rising curve, and it is also nonlinear. The results are similar for the negative current on the left side of the chart. From this we can conclude the following:

- due to the positive overlap, the output flow characteristic is relatively nonlinear with respect to the input signal,

- the valve has a large hysteresis,

- even after passing the centre dead zone, in a working range between $400 \mathrm{~mA}$ and $730 \mathrm{~mA}$, the valve has a nonlinear characteristic, and also,

- the maximum flows of the valves are different.

Although the three tested vales should be completely identical, Fig. 2 also reveals that valves 2 and 3 have much more equal characteristics than valve 1, which has a significantly 
increased hysteresis and a very nonlinear flow curve when the control spool is moved towards the centre position. In practice, when purchasing a new identical type valve, the user cannot be aware of these differences in the performance of identical type valves.

\section{SIMULATION MODEL}

The simulations and vast variety of simulation software cover a very wide range of engineering applications $[7,8]$. Simulink simulation software was chosen to investigate the difference in motor speed and position for uniform motion of two hydraulic motors controlled by two identical type proportional directional valves that, in reality, have minor different performance characteristics, as presented in section 2.2.

\subsection{Mathematical models}

Over the decades, researchers have developed several mathematical models to describe the operation of hydraulic pumps and motors. Since real hydraulic components, as well as their mathematical descriptions, are very complex due to their design, the authors have developed different proposals on how to approach the real model as closely as possible. Usually, the described model is simplified. In most cases, the output flow of a hydraulic component, e.g. a pump, is defined as the difference between ideal flow and flow losses - the "loss" model. In this manner, there are different mathematical models that are based on losses: Wilson Loss model [9], Schlösser Loss model [10], Olsson Loss model [11], Pacey, Turnquist and Clark Loss model [12], Zarotti and Nervenga Loss model [13], Rydberg Loss model [14], Bavendiek Loss model [15], Ivantysyn and Ivantysynova Loss model [16], Dorey Loss model [17], Kögl Loss model [18], Huhtala Loss model [19], Baum Loss model [20], Ortwig Loss model [21], Jeong Loss model [22]. In the presented simulation we will use simplified models, as we are not interested in the detailed behaviour of each component, but rather in the overall response of the system.

\subsection{Model of a hydraulic motor}

For the purposes of simulating uniform rotation, we will use a simplified model of a hydraulic motor [23], represented by Eqs. (1), (2) and (3). The equations include the effect of compressibility of the hydraulic fluid, and consider only the pressure dependency part of internal leakage, while the leakage, which depends on the shaft angle velocity, is neglected.

$$
\begin{gathered}
Q_{m}=D_{m} \omega_{m}+K_{m} \Delta p_{m} \\
J_{m} \frac{\mathrm{d} \omega_{m}}{\mathrm{~d} t}=D_{m} \Delta p_{m}-B_{m} \omega_{m}-\tau_{L} \\
\frac{\mathrm{d} \Delta p_{m}}{\mathrm{~d} t}=\frac{\beta}{V}\left(Q_{v}-Q_{m}\right)
\end{gathered}
$$

where: $Q_{m}$ - fluid flow rate delivered to the motor, $\Delta p_{m}$ - the pressure differential across the motor, $\tau_{m}$ - load torque applied on the motor shaft, $V$-volume of hydraulic fluid in the pipeline, $Q_{v}$ - fluid flow rate at the valve output; other definitions and constants are given in Table I:

Table I: Definitions and values for Eqs. (1) to (3) [23].

\begin{tabular}{|c|l|l|}
\hline Symbol & \multicolumn{1}{|c|}{ Definition } & \multicolumn{1}{c|}{ Value } \\
\hline$D_{m}$ & Motor displacement & $8.47 \mathrm{~cm} / \mathrm{rev}$ \\
\hline$J_{m}$ & Motor inertia & $0.0028 \mathrm{~kg} \cdot \mathrm{m}^{2}$ \\
\hline$B_{m}$ & Motor viscous damping & $0.00045 \mathrm{~N} \cdot \mathrm{m} / \mathrm{rpm}$ \\
\hline$K_{m}$ & Motor leakage coefficient & $15.92 \mathrm{~cm} / \mathrm{bar}$ \\
\hline$\beta$ & Fluid bulk modulus & $12670 \mathrm{bar}$ \\
\hline
\end{tabular}


A Simulink model, shown in Fig. 3, was designed according to Eqs. (1) to (3).

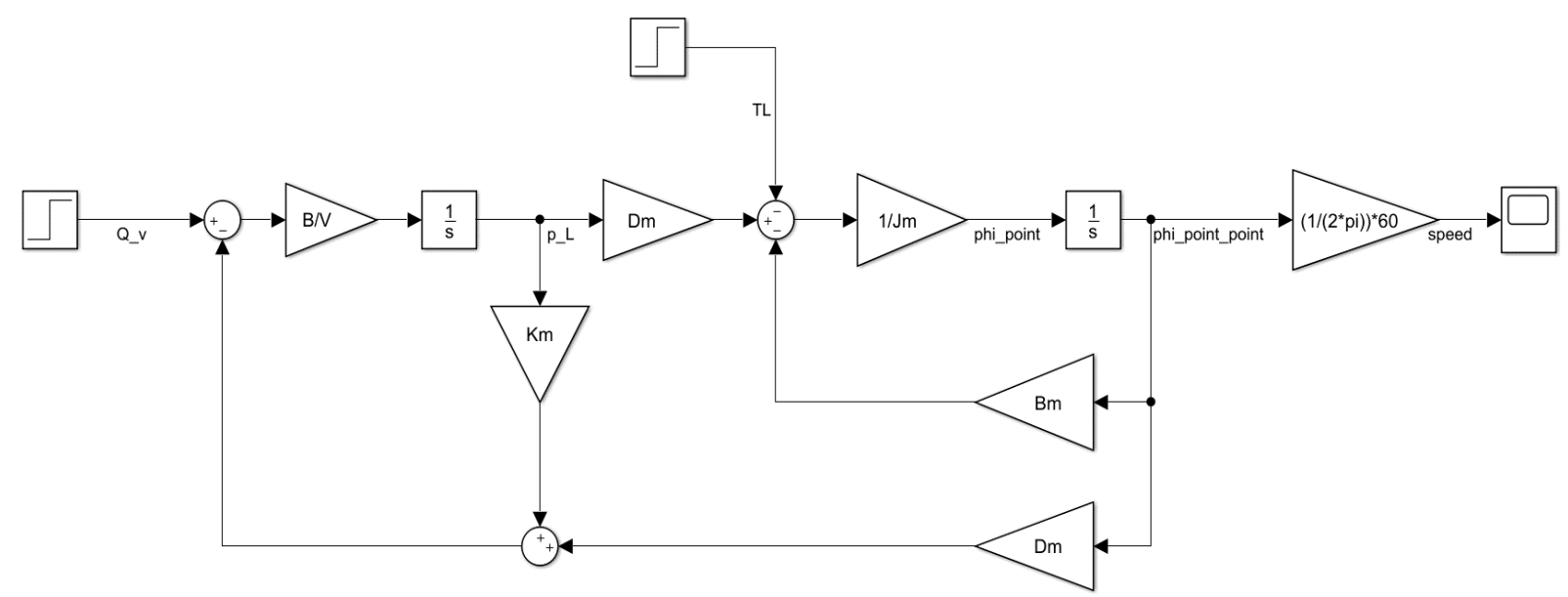

Figure 3: Simulink block diagram of a hydraulic motor.

\subsection{Model of the proportional directional valve}

The model of the proportional valve was built according to [24, 25]. The force balance equation can be written as:

$$
\sum F=F_{E}-F_{k}-F_{D}-F_{l}-F_{f}
$$

where $\Sigma F$ is the total force on the spool, $F_{E}$ is the electromagnetic force, $F_{k}$ is the spring force, $F_{D}$ is the viscous damping force, $F_{f}$ is the friction force, and $F_{l}$ is the fluid force inside the valve, which is small enough to be ignored.

The motion differential equation of the spool, determined from Eq. (4) is:

$$
m \ddot{x}=a i-k x-C \dot{x}-F_{\text {friction }}
$$

where $m$ is the mass of the valve spool, $\alpha$ is the magnetic coupling coefficient, $k$ is the spring rate, $C$ is the viscous damping coefficient, and $k f$ is the viscous friction coefficient.

The electric current through the solenoid can be described as:

$$
L \frac{\mathrm{d} i}{\mathrm{~d} t}+R_{i}=u-\alpha \frac{\mathrm{d} x}{\mathrm{~d} t}
$$

where $L$ and $R$ are the coil inductance and the coil resistance, $i$ is the current in the coil and $u$ is the applied voltage across the coil.

The flow rate through the valve is determined by:

$$
Q=C_{d} A \sqrt{\frac{2 \Delta P}{\rho}}
$$

where $Q$ is the valve flow rate, $C d$ is the flow rate coefficient, $A$ is the opening area of the valve, $\Delta P$ is the pressure difference, and $\rho$ is the density of the fluid. The flow rate $Q$ is proportional to $A$ and $A$ is proportional to the displacement of the spool $x$.

Hence, the flow rate $\mathrm{Q}$ is proportional to the displacement $x$ by a gain $K_{q}$ and can be expressed as:

$$
Q=K_{q} x
$$

The combination of Eqs. (5), (6) and (8) represents a mathematical model of the proportional valve presented in Fig. 4, where a LuGre friction model is used. 


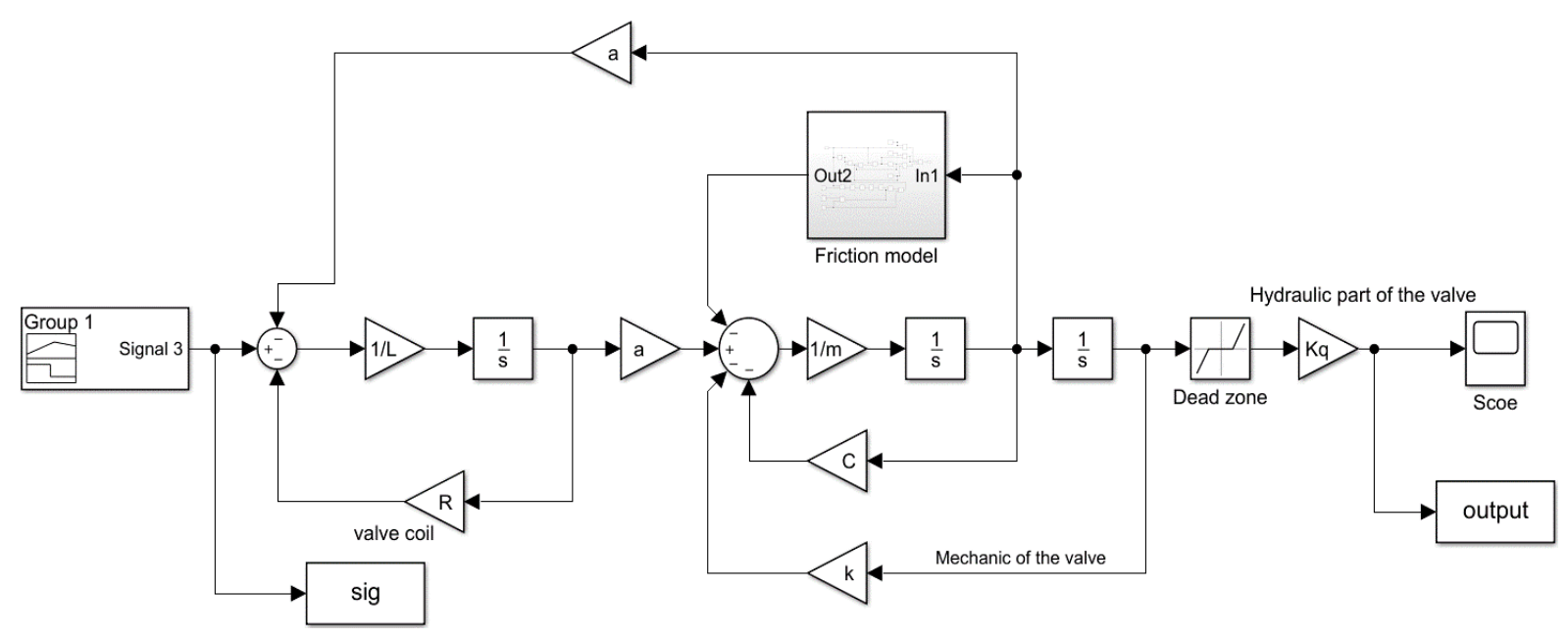

Figure 4: Simulink block diagram of a proportional directional valve.

The LuGre friction model, given by Eqs. (9), (10) and (11), was developed by Canudas de Wit, Olsson, Astrom and Lischinsky [26], and takes into account the Stribeck effect and socalled pre-sliding behaviour [25]:

$$
\begin{gathered}
F_{f}=\sigma_{o} z+\sigma_{1} \dot{z}+k_{v} v \\
\dot{z}=v-\frac{|v|}{g(v)} \\
g(v)=\frac{1}{\sigma_{0}}\left(F_{c}+\left(F_{s}-F_{c}\right) e^{-\left(\frac{|v|}{v_{s}}\right)^{i}}\right.
\end{gathered}
$$

where $F_{f}$ is the friction force, $\sigma_{0}$ and $\sigma_{1}$ are dynamic parameters, which are, respectively, the frictional stiffness and frictional damping, $z$ is the average deflection of the contacting asperities, $v=\dot{x}$ is the velocity of motion, $k_{v}$ is the viscous coefficient, $F_{c}$ is the Coulomb sliding friction force, $F_{s}$ is the static friction force, $v_{s}$ is the Stribeck velocity, and $i$ is the Stribeck shape factor.

A Simulnik model, shown in Fig. 5, was designed according to Eqs. (9) to (11). The individual parameters and constants were determined based on the real measurements of the Hawe NWSP 2G 20 valves, presented in section 2.2, and are shown in Table II.

Table II: Values and constants used in valve 1 (V1) and valve 2 (V2) and the LuGre model.

\begin{tabular}{|c|c||c|c|}
\hline \multicolumn{2}{|c||}{ Valve model } & \multicolumn{2}{c|}{ LuGre model } \\
\hline Symbol and value & Definition & Symbol and value & Definition \\
\hline$m=0.4 \mathrm{~kg}$ & Solenoid core mass & $F c=0.1 \mathrm{~N}$ & Coulomb friction force \\
\hline$R=100 \Omega$ & Coil resistance & $\begin{array}{c}F s=0.2 \mathrm{~N} \quad(\mathrm{~V} 1) \\
F s=0.15 \mathrm{~N}(\mathrm{~V} 2)\end{array}$ & Static friction force \\
\hline$L=0.1 \mathrm{H}$ & Coil inductivity & $\begin{array}{c}v s=0.007 \mathrm{~m} / \mathrm{s}(\mathrm{V} 1) \\
v s=0.0001 \mathrm{~m} / \mathrm{s}(\mathrm{V} 2)\end{array}$ & Stribeck velocity \\
\hline$a=20 \mathrm{~V} \cdot \mathrm{s} \cdot \mathrm{m}^{-1}$ & Magnet coefficient & $o 0=10^{5} \mathrm{Ns} / \mathrm{m}$ & Stiffness coefficient \\
\hline$k=17000 \mathrm{~N} \cdot \mathrm{m}^{-1}$ & Spring coefficient & $o 1=470 \mathrm{Ns} / \mathrm{m}$ & Damping coefficient \\
\hline$C=0.2$ & Viscous damping coeff. & $o 2=0.2 \mathrm{~N} \cdot \mathrm{s} \cdot \mathrm{m}^{-1}$ & Viscosity friction \\
\hline$K q=476106$ (V1) & Gain & $j=2$ & Shape coefficient \\
$K q=315000$ (V2) & & & \\
\hline
\end{tabular}




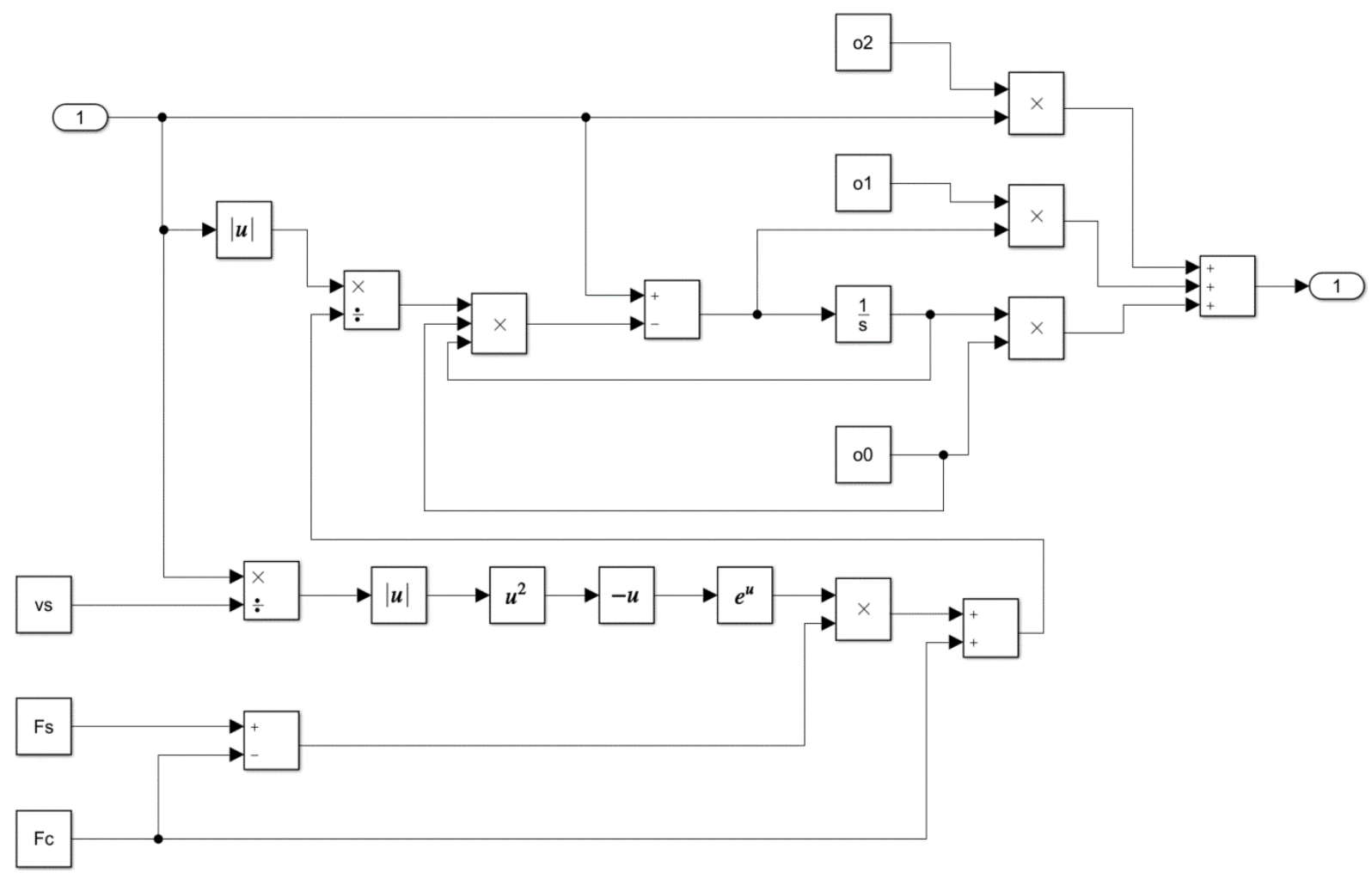

Figure 5: Simulink block diagram of a LuGre friction model.

\subsection{Model of a PID controller}

The most frequently and commonly used controllers in industrial closed loop applications are PID controllers. The controller consists of 3 parts: The proportional, integral, and differential parts. In the presented simulation we have implemented a so-called ideal PID controller, given by Eq. (12).

$$
u(t)=K_{p}\left(e(t)+\frac{1}{T_{i}} \int_{t_{0}}^{t} e(t) \mathrm{d} t+T_{d} \frac{\mathrm{d} e(t)}{\mathrm{d} t}\right)
$$

The PID controller used in the simulation was optimised with a built-in PID Tuner tool. Due to the deviation of the valve's performance, the settings of each PID controller are also different. The controller constants for each proportional valve are given in Table III.

Table III: Controller constants for each proportional valve.

\begin{tabular}{|c|c|c|}
\hline Constant & Proportional valve V1 & Proportional valve V2 \\
\hline$K_{p}$ & 0.016 & 0.023 \\
\hline$T_{i}$ & 0.156 & 0.150 \\
\hline$T_{d}$ & 0.005 & 0.000 \\
\hline
\end{tabular}

\subsection{Uniform motion of two hydraulic motors using two proportional valves}

Fig. 6 presents the Simulink block diagram of the simulation of the uniform motion of two hydraulic motors using two proportional valves to investigate the performance of motor synchronization using two conventional proportional valves of identical type, but with different characteristics. Motor 1 is controlled by proportional valve V1, and motor 2 is controlled by proportional valve V2. 


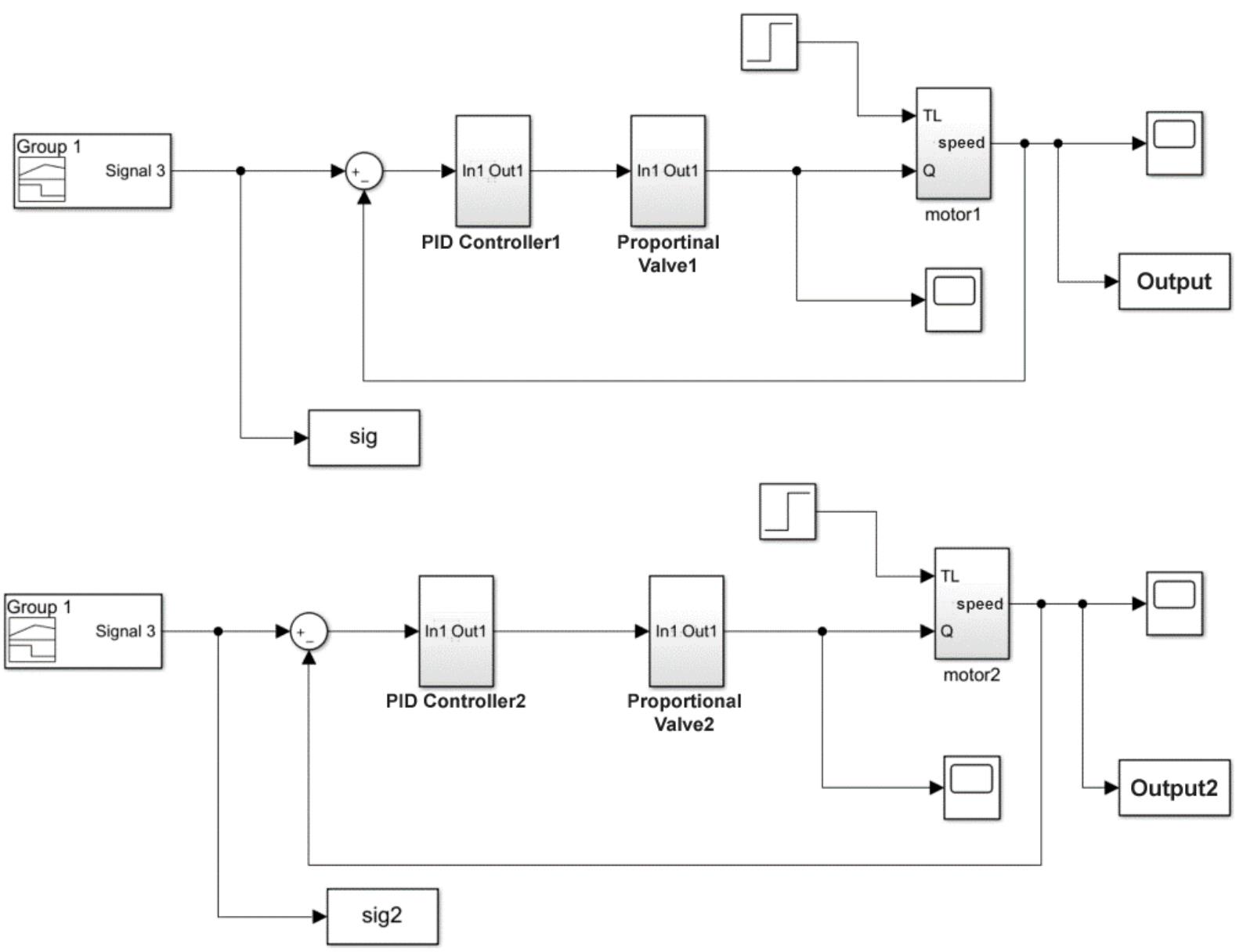

Figure 6: Block diagram of uniform motion of two hydraulic motors using two conventional proportional valves.

\section{RESULTS}

With regard to the different characteristics and performance of the identical valve types, we want to compare the impact of their differences on the response of the system. By operating the hydraulic motor in both forward and reverse directions, we bring in and acquire the influence of hysteresis and the dead zone of the valves.

\subsection{System step response to change of desired speed setpoint}

The system step response to change of desire speed setpoint was investigated first. At the beginning of the simulation, the hydraulic motor desired speed setpoint was changed from $0 \mathrm{rpm}$ to $600 \mathrm{rpm}$ in a forward direction. At a time of 2 seconds, the desired motor speed was reversed to $-200 \mathrm{rpm}$, and at a time of 4 seconds, the desired motor speed was set back to a forward direction of $600 \mathrm{rpm}$. No additional external load torque was used in this simulation.

System step response to the trajectory of the desired speed setpoint is shown in Fig. 7. Comparison of speeds of hydraulic motors 1 and 2 reveals significant differences when the desired speed setpoint was changed, since the identical type valves do not have the same performance characteristics, and, consequently, the settings of PID controllers also differ. Examining the results, the difference in hydraulic motor speed is up to $175 \mathrm{rpm}$, which corresponds to $30 \%$ of the desired speed setpoint. 

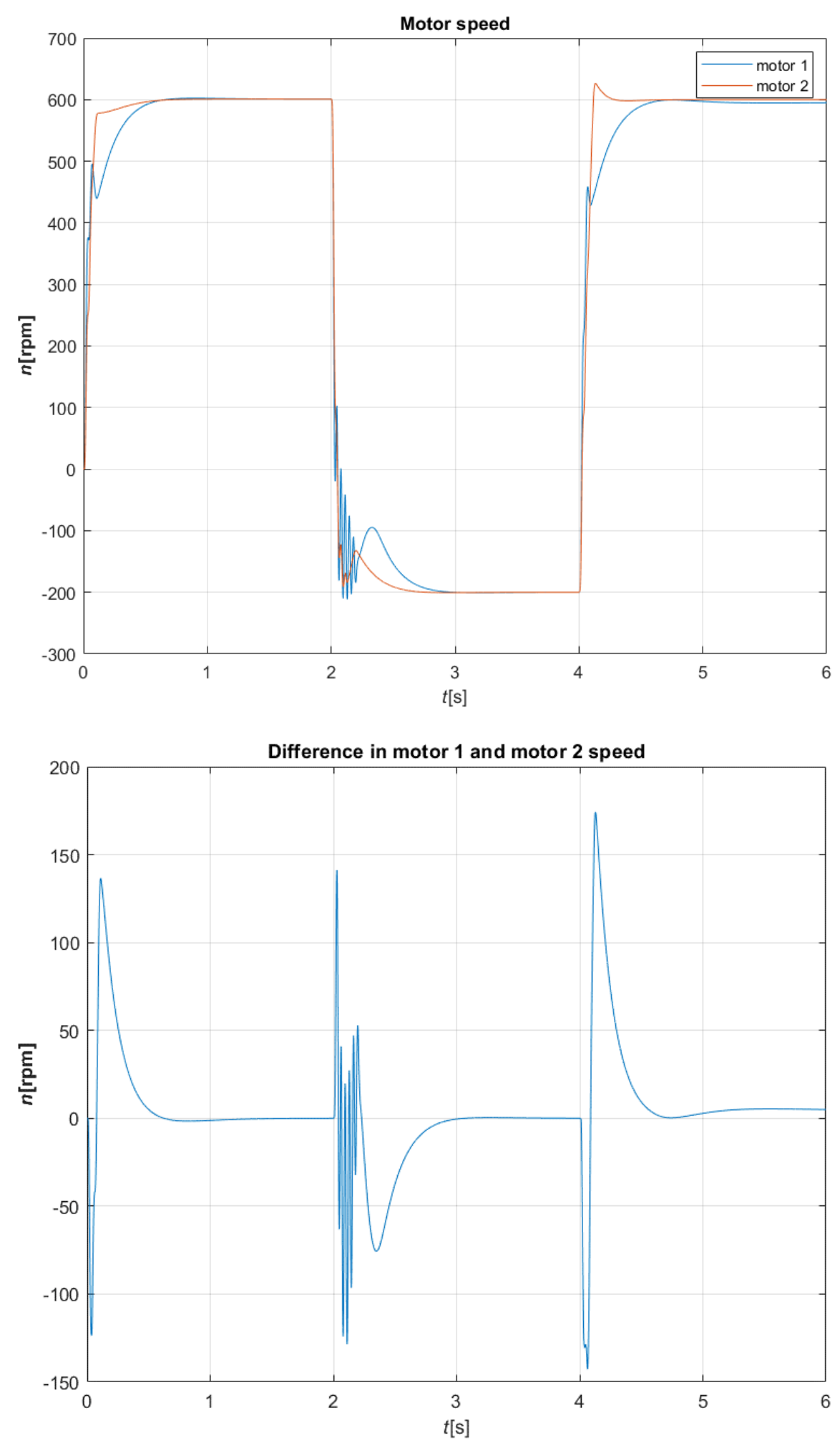

Figure 7: System step response to the trajectory of the desired speed setpoint.

\subsection{System step response to change of motor load torque}

The system step response to change of motor load torque was investigated next. At the beginning of the simulation, the hydraulic motor desired speed setpoint was changed from $0 \mathrm{rpm}$ to $600 \mathrm{rpm}$ in a forward direction, with load torque of $10 \%$ of the hydraulic motor nominal load torque. At time of 2 seconds, the load torque was increased from $10 \%$ to $100 \%$ of the hydraulic motor nominal load torque. 

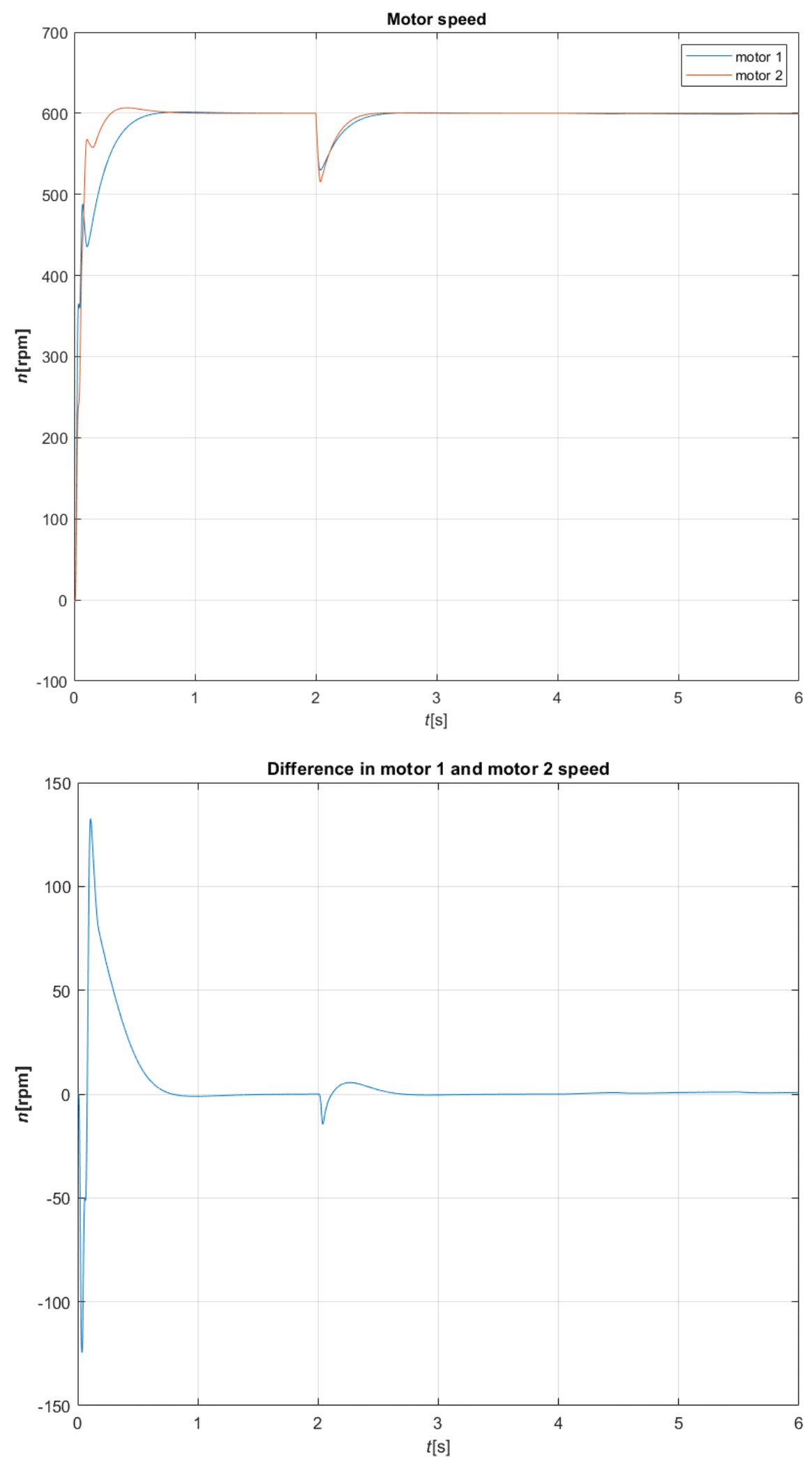

Figure 8: System step response to change of motor load torque.

The system step response to change of motor load torque, described above, is presented in Fig. 8. Comparison of the speeds of hydraulic motors 1 and 2 shows a minor difference in motor speed of $12 \mathrm{rpm}$ when load torque on the motor was changed, which corresponds to $2 \%$ of the desired speed setpoint. 


\section{CONCLUSION}

As pointed out in the Introduction, the simplest methods for achieving uniform motion of hydraulic actuators or motors use mechanical-hydraulic solutions. They represent an easy implementation of synchronization for use in non-demanding applications, and are poorly flexible with limited accuracy. By using electro-hydraulic solutions, we can design and realise much better and more accurate uniform rotation of hydraulic motors, especially when servo vales or proportional control valves are used (with closed-loop position control of the valve's spool).

On the other hand, if simple proportional valves are used, it is important to be aware that the same valve characteristics are essential to minimise errors. Thus, it makes sense to perform static and dynamic measurements of valve characteristics to predict the behaviour of the valve.

By performing the presented simulations, we proved that the dead zone, hysteresis, nonlinearity and other characteristics affect the quality of synchronization of two identical type valves significantly, especially in the area of sudden transients. Based on the simulation results, we can conclude that simple proportional valves cannot be used directly to achieve a high degree of uniform motion, but rather servo vales or proportional control valves should be used. Namely, if simple proportional valves are used for uniform motion of two hydraulic motors, we can expect up to $30 \%$ difference in motor speed when the desired motor speed is changed for a period up to 1 second, before the same speed on two motors is achieved again. On the other hand, when the motor load is changed, the differences are much smaller. However, by identifying the characteristics of the valve and by using suitable control concepts, it is possible to achieve a high degree of uniform motion, despite various differences resulting from nonidentical control components, actuators, or other causes, such as uneven actuator load or different degree of wear.

\section{REFERENCES}

[1] Hu, X. P. (2020). Cooperative automatic control for the canopy posture of a four-leg hydraulic support, International Journal of Simulation Modelling, Vol. 19, No. 4, 713-724, doi:10.2507/IJSIMM19-4-CO20

[2] Jurkovic, M.; Jurkovic, Z.; Buljan, S.; Obad, M. (2018). An experimental and modelling approach for improving utilization rate of the cold roll forming production line, Advances in Production Engineering \& Management, Vol. 13, No. 1, 57-68, doi:10.14743/apem2018.1.273

[3] Zhang, T.; Wang, Q.; He, X.-H.; Li, S.-S.; Shen, X.-M. (2020). Power-following control strategy of a wheel-drive hydraulic hybrid vehicle, Strojniški vestnik-Journal of Mechanical Engineering, Vol. 66, No. 3, 193-202, doi:10.5545/sv-jme.2019.6302

[4] Banaszek, A.; Petrovic, R. (2019). Problem of non proportional flow of hydraulic pumps working with constant pressure regulators in big power multipump power pack unit in open system, Technical Gazette, Vol. 26, No. 2, 294-301, doi:10.17559/TV-20161119215558

[5] Totten, G. E.; de Negri, V. J. (2011). Handbook of Hydraulic Fluid Technology, $2^{\text {nd }}$ edition, Boca Raton, CRC Press, doi: $10.1201 / \mathrm{b} 11225$

[6] Tic, V.; Lovrec, D. (2019). Test device and automated test procedures for measuring valve characteristics, Proceedings of International Conference Fluid Power 2019, 147-158, doi: $10.18690 / 978-961-286-300-5.12$

[7] Turk, M.; Pipan, M.; Simic, M.; Herakovic, N. (2020). Simulation-based time evaluation of basic manual assembly tasks, Advances in Production Engineering \& Management, Vol. 15, No. 3, 331344, doi:10.14743/apem2020.3.369

[8] Yu, Y. X.; Ke, S. D.; Jin, K. D. (2020). Structural parameters optimization for a proportional solenoid, International Journal of Simulation Modelling, Vol. 19, No. 4, 689-700, doi:10.2507/IJSIMM19-4-CO18

[9] Wilson, W. E. (1949). Performance criteria for positive displacement pumps and fluid motors, Transactions of the American Society of Mechanical Engineers, Vol. 71, No. 2, 115-120 
[10] Schlösser, W. M. J. (1961). Mathematical model for displacement pump and motors, Hydraulic Power Transmission, Vol. 7, 252-328

[11] Olsson, O. (1973). Matematisk Verkingsgrad Modell, Kompendium i Hydraulik (eng.: Mathematical Efficiency Model, Compendium in Hydraulics), LiTHIKP, Institute of Technology, Linköping (in Swedish)

[12] Pacey, D. A.; Turnquist, R. O.; Clark, S. J. (1979). The development of a coefficient model for hydrostatic transmissions, Proceedings of the $35^{\text {th }}$ National Conference in Fluid Power, 173-178

[13] Zarotti, G. L.; Nervegna, N. (1982). Pump efficiencies: approximation and modelling, Fluidics Quartelrly, Vol. 14, No. 3, 1-20

[14] Rydberg, K. E. (1983). On Performance Optimization and Digital Control of Hydrostatic Drives for Vehicle Applications, PhD Thesis, Linkoeping University of Technology, Linkoeping

[15] Bavendiek, R. (1988). Verlustkennwertbestimmung am beispiel von hydrostatischen maschinen in schrägachsenbauweise, Forschung im Ingenieurwesen, Vol. 54, No. 3, 93-93, doi:10.1007/ BF02582097

[16] Ivantysyn, J.; Ivantysynova, M. (2003). Hydrostatic Pumps and Motors: Principles, Design, Performance, Modelling, Analysis, Control and Testing, Tech Books International, New Delhi

[17] Dorey, R. E. (1988). Modelling of losses in pumps and motors, Proceedings of the First Bath International Fluid Power Workshop, 71-97

[18] Kögl, C. (1995). Verstellbare Hydrostatische Verdrängereinheiten im Drehzahl- und Drehmomentregelkreis am Netz mit Angepaßtem Versorgungsdruck, PhD Thesis, Aachen University, Aachen

[19] Huhtala, K. (1996). Modelling of Hydrostatic Transmission - Steady State, Linear and Non-linear Models, PhD Thesis, The Finnish Academy of Technology, Helsinki

[20] Baum, H. (2001). Einsatzpotenziale Neuronaler Netze bei der CAE-Tool Unterstützten Projektierung Fluidtechnischer Antriebe, PhD Thesis, Aachen University, Aachen

[21] Ortwig, H. (2002). New method of numerical calculation of losses and efficiencies in hydrostatic power transmissions, SAE Technical Paper, Paper 2002-01-1418, 14 pages, doi:10.4271/2002-01$\underline{1418}$

[22] Jeong, H.-S. (2007). A novel performance model given by the physical dimensions of hydraulic axial piston motors: model derivation, Journal of Mechanical Science and Technology, Vol. 21, No. 1, 83-97, doi:10.1007/BF03161714

[23] Deldar, M.; Izadian, A.; Anwar, S. (2013). Modeling of a hydraulic wind power transfer system utilizing a proportional valve, Proceedings of the 2003 IEEE Energy Conversion Congress and Exposition, 3311-3316, doi:10.1109/ECCE.2013.6647135

[24] Wachholz, L. C.; Valdiero, A. C.; Razia. L. A. (2019). Mathematical modeling of a hydraulic motor operated and controlled by proportional valve, Proceedings of the $25^{\text {th }}$ ABCM International Congress of Mechanical Engineering, Paper COB-2019-2272, 11 pages, doi:10.26678/ ABCM.COBEM2019.COB2019-2272

[25] Vo, V. (2017). Hysteresis Reduction in Hydraulic Proportional Valve Control: Tuning Parameters in Dither Compensation Method, Bachelor Thesis, Hame University of Applied Sciences, Hameenlinna

[26] Canudas de Wit, C.; Olsson, H.; Astrom, K. J.; Lischinsky, P. (1995). A new model for control of systems with friction, IEEE Transactions on Automatic Control, Vol. 40, No. 3, 419-425, doi: $\underline{10.1109 / 9.376053}$ 